\title{
Di-ureasil xerogels containing lithium bis(trifluoromethanesulfonyl)imide for application in solid-state electrochromic devices
}

\author{
Paula C. Barbosa ${ }^{a}$, M. Manuela Silva ${ }^{a, *, 1}$, Michael J. Smith ${ }^{a}$, Alexandra Gonçalves ${ }^{\mathrm{b}}$, \\ Elvira Fortunato ${ }^{\mathrm{b}}$, Sílvia C. Nunes ${ }^{\mathrm{c}}$, V. de Zea Bermudez ${ }^{\mathrm{c}}$ \\ a Departamento de Química, Universidade do Minho, Gualtar, 4710-057 Braga, Portugal \\ b Centro de Investigação de Materiais, CENIMAT, Campus da Caparica FCT, 2829-516 Caparica, Portugal

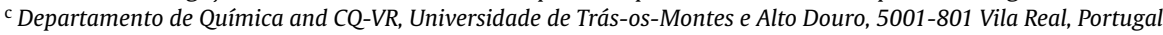

\section{A R T I C L E I N F O}

\section{Article history:}

Received 16 April 2008

Received in revised form 17 July 2008

Accepted 1 August 2008

Available online 22 August 2008

\section{Keywords:}

Di-ureasils

Sol-gel

All-solid-state electrochromic displays

Solid polymer electrolytes

Organic-inorganic hybrid networks

\begin{abstract}
A B S T R A C T
In this study we report the characterization of a prototype solid-state electrochromic device based on poly(ethylene oxide) (PEO)/siloxane hybrid networks doped with lithium bis(trifluoromethanesulfonyl)imide (LiTFSI). The polymer networks prepared, designated as di-ureasils and represented as $\mathrm{d}-\mathrm{U}(2000)$, were produced by a sol-gel procedure and are composed of a siliceous framework to which both ends of polyether chains containing about $40-\mathrm{CH}_{2} \mathrm{CH}_{2} \mathrm{O}-$ units are covalently bonded through urea linkages. Samples with compositions of $200 \geq n \geq 0.5$ (where $n$ is the molar ratio of $-\mathrm{CH}_{2} \mathrm{CH}_{2} \mathrm{O}-$ to $\mathrm{Li}^{+}$) were characterized by thermal analysis, complex impedance measurements and cyclic voltammetry at a gold microelectrode. Electrolyte samples were obtained as self-supporting, transparent, amorphous films and at room temperature the highest conductivity was observed with the d-U $(2000)_{35}$ LiTFSI composition $\left(3.2 \times 10^{-5} \Omega^{-1} \mathrm{~cm}^{-1}\right)$. We report the results of preliminary evaluation of these polymer electrolytes as multi-functional components in prototype electrochromic displays. Device performance parameters such as coloration efficiency, optical contrast and image stability were also evaluated. The electrolytes with $n>8$ presented an optical density above 0.56 and display assemblies exhibited good open-circuit memory and stable electrochromic performances.
\end{abstract}

(c) 2008 Elsevier Ltd. All rights reserved.

\section{Introduction}

During the last decade the development of new strategies that result in the reduction of energy consumption or improvements in the efficiency of energy conversion have attracted significant industrial and academic interest. Part of the resulting research effort has been devoted to the study of devices such as photovoltaic cells, rechargeable batteries and, more recently, electrochromic displays with potential application as smart windows or time-lapse labels. Electrochromic devices are able to reversibly modulate optical transmission through the application of a low voltage. The application of these devices may provide greater energy savings than conventional fixed-state solar control and shading devices $[1,2]$. One of the most important components of smart windows is the electrolyte layer. This should support ionic conductivity, be a good electronic insulator under open-circuit potential and show

\footnotetext{
* Corresponding author. Tel.: +351 253604370/86; fax: +351 253604382

E-mail address: nini@quimica.uminho.pt (M.M. Silva).

1 ISE member.
}

good thermal, chemical and electrochemical stability [3]. Although solid polymer electrolytes have been extensively studied for application in advanced primary and secondary batteries, they also fulfill the prerequisites for electrochromic displays and offer a promising alternative to conventional liquid-based electrolytes. The risks of solvent loss through leakage or evaporation and solvent-related damage to active electrode materials are eliminated and additional adhesive, separator and sealing functionality is provided. In energy storage applications the ionic conductivity is of paramount importance as the power density of the device may be conditioned by this aspect of electrolyte performance. The conductivity of the electrolyte component in display assemblies also influences device behaviour. In this case however, as an instantaneous optical response is not essential, a lower total ionic conductivity is quite acceptable.

Silica-based hybrid electrolytes formed under mild reaction conditions by grafting oligopolyoxyethylene chains onto a siliceous network [4], have been shown to provide suitable characteristics for a wide range of practical applications including batteries, data storage devices, sensors and optical displays [5-7]. The sub-class of solid electrolytes designated as ormolytes (organically modified electrolytes) has attracted particular attention in the past few years 
[8-10], as they combine high optical transparency, an essential property for electrochromic and photochromic devices, with good ionic conductivity. In agreement with the terminology adopted in previous publications [11,12], the ormolytes were identified using the $d-U(2000)_{n}$ LiTFSI notation, where $d-U(2000)$ represents the host di-ureasil framework ( $\mathrm{d}$ stands for di, $\mathrm{U}$ denotes the urea group and 2000 corresponds to the average molecular weight of the organic precursor) and $n$ (salt composition) indicates the number of ether oxygen atoms per $\mathrm{Li}^{+}$cation.

In this study sol-gel synthesis was used to prepare thinfilm electrolytes based on di-ureasils incorporating long-chain oxyethylene segments $\left(2000 \mathrm{~g} \mathrm{~mol}^{-1}\right)$ and containing LiTFSI. The use of Jeffamine 2001 as a precursor was expected to provide an improvement, relative to previously characterized networks [13], in both physical and electrochemical properties. The LiTFSI salt was selected for this study as a well-dissociated salt with useful plasticizing characteristics, one of the most promising guest salt species used in oxyethylene-based electrolytes [14,15]. The electrochemical and thermal behaviour reported confirms expectations that the choice of this salt provides access to physical properties comparable to those of lithium perchlorate-doped networks and higher ionic conductivities. As noted previously [15], the use of LiTFSI rather than lithium perchlorate, avoids possible inconvenience of exothermic degradation observed with this latter guest salt. The assembly and preliminary evaluation of a prototype solid-state electrochromic device, based on a four-layer sandwich structure with a glass/electronic conductor/ $\mathrm{WO}_{3} /$ ormolyte/electronic conductor/glass configuration, demonstrated that both mechanical and electrochemical characteristics led to improved operation of a prototype optical display.

\section{Experimental}

\subsection{Materials}

Lithium bis(trifluoromethanesulfonyl)imide $\left(\mathrm{LiN}\left(\mathrm{SO}_{2} \mathrm{CF}_{3}\right)_{2}\right)$ was dried under vacuum at $190^{\circ} \mathrm{C}$ for 7 days and then stored in anhydrous conditions within a dry argon-filled glovebox. The $\alpha, \beta$-diamine poly(oxyethylene-co-oxypropylene) (commercially available as Jeffamine ED-2001 ${ }^{\circledR}$, Fluka, average molecular weight $2001 \mathrm{~g} \mathrm{~mol}^{-1}$ ) was dried under vacuum at $25^{\circ} \mathrm{C}$ for several days prior to use. The bridging agent, 3-isocyanatepropyltriethoxysilane (ICPTES, Aldrich, 95\%), was used as received. Ethanol $\left(\mathrm{CH}_{3} \mathrm{CH}_{2} \mathrm{OH}\right.$, Merck, 99.8\%) and tetrahydrofuran (THF, Merck, 99.9\%) were dried over molecular sieves. High purity distilled water was used in all experiments.

\subsection{Sample preparation}

\subsubsection{Preparation of the di-ureasil ormolytes}

The synthetic procedure used to prepare the LiTFSI-based diureasils involved grafting a PEO-based diamine onto the ICPTES substrate to yield the di-urea $(-\mathrm{NH}(\mathrm{C}=\mathrm{O}) \mathrm{NH}-)$ bridged hybrid molecule. This precursor was subsequently hydrolyzed and condensed in the sol-gel stage to induce the growth of the siloxane network (Scheme 1) [11,12].

2.2.1.1. Step 1. Synthesis of the di-ureasil precursor, dUPTES(2000): $2.0 \mathrm{~g}$ of Jeffamine ED-2001 were dissolved in $10 \mathrm{ml}$ of THF by stirring. A volume of $0.494 \mathrm{ml}$ of ICPTES was added to this solution in a fume cupboard. The flask was then sealed and<smiles>CC(N)CCOCCCCC(C)C(C)N</smiles>

$\alpha, \omega$-diaminepoly(oxyethylene-co-oxypropylene)

Jeffamine ED-2000 ( $b=40.5$ and $a+c=2.5)$
$2 \underset{\mathrm{H}_{3} \mathrm{CH}_{2} \mathrm{CO}-\mathrm{Si}-\left(\mathrm{CH}_{2}\right)_{3}-\mathrm{N}=\mathrm{C}=\mathrm{O}}{\mathrm{H}_{3} \mathrm{CH}_{2} \mathrm{CO}^{\prime}}$

3-isocyanatepropyltriethoxysilane

ICPTES

THF
$\mathbf{4 0}^{\circ} \mathbf{C}$

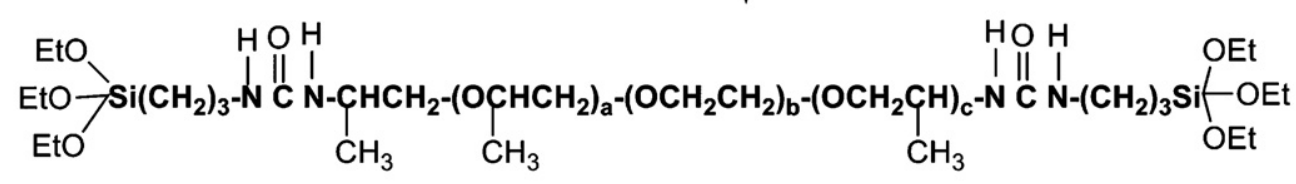

di-ureapropyltriethoxysilane(2000) precursor

d-UPTES(2000)

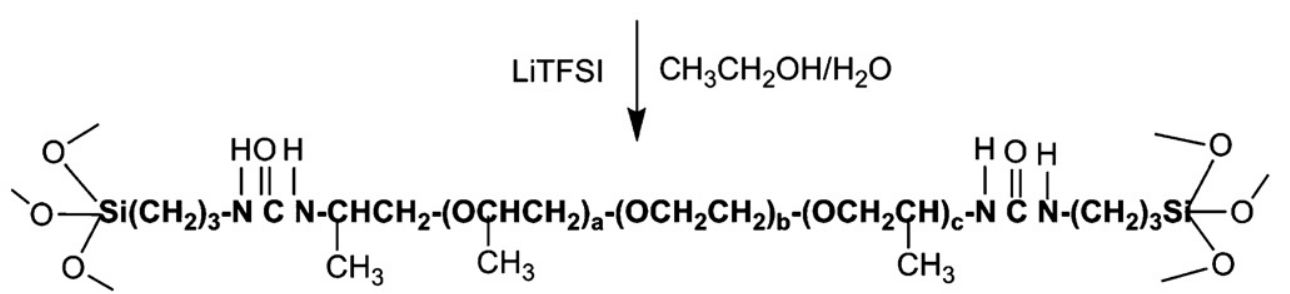

d-U(2000) $)_{n}$ LiTFSI hybrids

Scheme 1. Synthesis of the d-U(2000) $)_{n}$ LiTFSI electrolyes. 
the solution stirred for about $12 \mathrm{~h}$ at a moderate reaction temperature of $40^{\circ} \mathrm{C}$. A urea bridged organic/inorganic hybrid material, designated as di-ureapropyltriethoxysilane (d-UPTES(2000)), was obtained.

2.2.1.2. Step 2. Synthesis of the di-ureasil xerogels, d$\mathrm{U}(2000)_{n}$ LiTFSI: A volume of $0.467 \mathrm{ml}$ of ethanol, an appropriate mass of LiTFSI and $0.054 \mathrm{ml}$ of water were added to the dUPTES(2000) solution prepared in the previous step (molar proportion 1 ICPTES: $4 \mathrm{CH}_{3} \mathrm{CH}_{2} \mathrm{OH}: 1.5 \mathrm{H}_{2} \mathrm{O}$ ). The mixture was stirred in a sealed flask for approximately $30 \mathrm{~min}$, cast into a Teflon mould, covered with Parafilm and left in a fume cupboard for $24 \mathrm{~h}$. The mould was transferred to an oven at $50^{\circ} \mathrm{C}$ and the sample was aged for a period of 4 weeks.

\subsubsection{Preparation of the conductive oxide films}

The indium zinc oxide (IZO) was deposited on glass substrates by r.f. (13.56 MHz) magnetron sputtering using a ceramic oxide target of $\mathrm{ZnO} / \mathrm{In}_{2} \mathrm{O}_{3}$ ( $5 \mathrm{~cm}$ diameter, Super Conductor Material, Inc., 99.99\% purity). Sputtering was carried out at room temperature, under a partial pressure of oxygen of $2.5 \times 10^{-3} \mathrm{~Pa}$ with a constant deposition pressure of $0.15 \mathrm{~Pa}$. The distance between the substrate and the target was $10 \mathrm{~cm}$ and the r.f. power was held constant at $100 \mathrm{~W}[16]$.

\subsubsection{Preparation of the electrochromic films}

The tungsten oxide films $\left(\mathrm{WO}_{3}\right)$ were prepared by thermal evaporation using $\mathrm{WO}_{3}$ pellets (Super Conductor Materials, Inc., 99.99\% purity) with a deposition pressure of $1.6 \times 10^{-3} \mathrm{~Pa}$.

\subsubsection{Preparation of the ECD}

The device assembly was carried out by direct application of a small volume of the $\mathrm{d}-\mathrm{U}(2000)_{n}$ LiTFSI gel to the surface of a glass plate onto which a $\mathrm{IZO} / \mathrm{WO}_{3}$ coating had been previously deposited. The gel was dried in a vacuum oven for a period of 7 days. Typical film thicknesses were $170 \mathrm{~nm}$ for IZO and $400 \mathrm{~nm}$ for $\mathrm{WO}_{3}$. A second IZO-coated glass plate was placed on top of the dry electrolyte layer and the two plates were pressed together to spread the electrolyte in a thin film between the electrochromic surfaces. In this manner a surface with an area of approximately $2 \mathrm{~cm}^{2}$ was formed. The entire assembly procedure described was carried out under atmospheric conditions. The assembled prototype solidstate electrochromic device structure is schematically represented in Fig. 1.

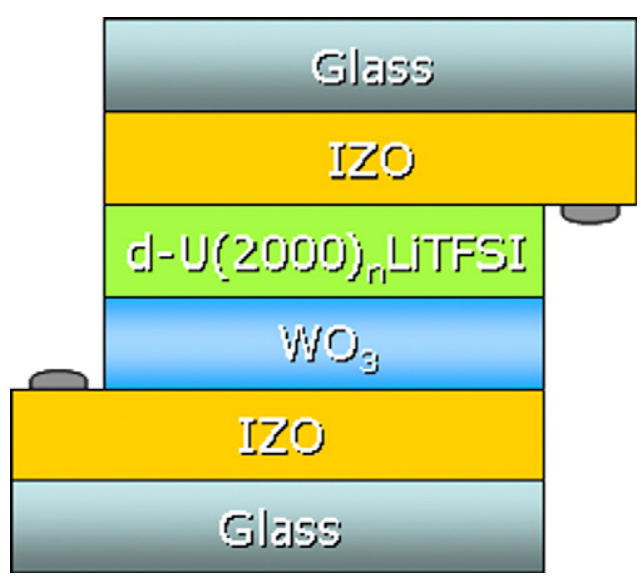

Fig. 1. Schematic diagram of the prototype electrochromic device structure.

\subsection{Experimental techniques}

\subsubsection{Ionic conductivity}

The total ionic conductivity of the ormolyte was determined by locating an electrolyte disk between two $10 \mathrm{~mm}$ diameter ion-blocking gold electrodes (Goodfellow, >99.95\%) to form a symmetrical cell. The electrode/d-U(2000) $)_{n}$ LiTFSI/electrode assembly was secured in a suitable constant volume support [17], and installed in a Buchi TO51 tube oven with a type K thermocouple placed close to electrolyte disk to measure the sample temperature. Bulk conductivities of electrolyte samples were obtained during heating cycles using the complex plane impedance technique (Schlumberger Solartron 1250 frequency response analyzer and 1286 electrochemical interface) between 25 and $100^{\circ} \mathrm{C}$ and at approximately $7^{\circ} \mathrm{C}$ intervals.

\subsubsection{Thermal analysis}

Sections were removed from dry films and subjected to thermal analysis under a flowing argon atmosphere between 25 and $300^{\circ} \mathrm{C}$ and at a heating rate of $5^{\circ} \mathrm{C} \mathrm{min}^{-1}$ using a Mettler DSC 821e. Samples were transferred to $40 \mu \mathrm{l}$ aluminium cans with perforated lids within a dry argon-filled glovebox. Samples for thermogravimetric studies were prepared in a similar manner, transferred to open crucibles and analyzed using a Rheometric Scientific TG1000 thermobalance operating under flowing argon.

\subsubsection{Electrochemical stability}

Evaluation of the electrochemical stability window of electrolyte compositions was carried out within a dry argon-filled glovebox using a two-electrode cell configuration. The preparation of a $25 \mu \mathrm{m}$ diameter gold microelectrode surface by the conventional polishing routine was completed outside the glovebox. The microelectrode was then washed with THF, dried with a hot-air blower and transferred to the glovebox. Cell assembly was initiated by locating a freshly cleaned lithium disk counter electrode $(10 \mathrm{~mm}$ diameter, $1 \mathrm{~mm}$ thick, Aldrich, 99.9\% purity) on a stainless steel current collector. A thin-film sample of ormolyte was centered over the counter electrode and the cell assembly completed by locating and supporting the microelectrode in the centre of the electrolyte disk. The assembly was held together firmly with a clamp and electrical contacts were made to the Autolab PGSTAT-12 (Eco Chemie) used to record voltammograms at a scan rate of $100 \mathrm{mV} \mathrm{s}^{-1}$. Measurements were conducted at room temperature within a Faraday cage located inside the measurement glovebox.

\subsubsection{Device fabrication and characterization}

The optical transmittance was measured using a UV-vis-NIR double beam spectrophotometer (UV-3100 PC, Shimadzu) over the wavelength range from 300 to $900 \mathrm{~nm}$. The coloring and bleaching voltages were 3.5 and $-1.5 \mathrm{~V}$ during 4 and $2 \mathrm{~min}$, respectively.

\section{Results and discussion}

\subsection{Conductivity measurements}

Almost two decades after the description of the first use of lithium bis(trifluoromethanesulfonyl) imide LiTFSI as a guest species in solid polymer electrolytes [18], this salt continues to be one of the best choices of components. In common with other salts that contain large polarizable anions, LiTFSI has a low lattice energy and a low tendency to form ion-pairs, leading to enhanced ionic mobility. This salt also performs as a plasticizer in polyether electrolytes by creating free-volume, this is a significant advantage in polymer hosts that have an inherent tendency to crystallize. 
$\mathrm{T}\left({ }^{\circ} \mathrm{C}\right)$

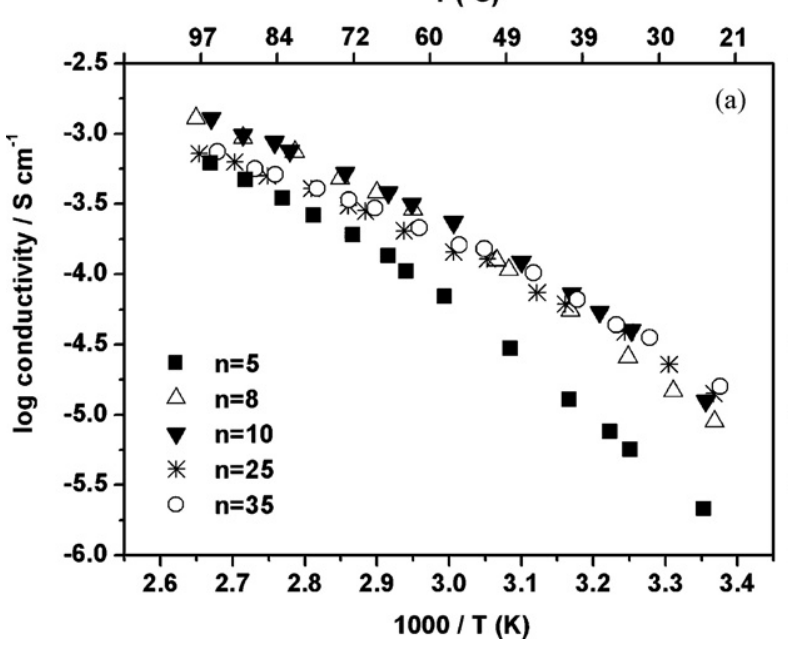

$\mathrm{T}\left({ }^{\circ} \mathrm{C}\right)$

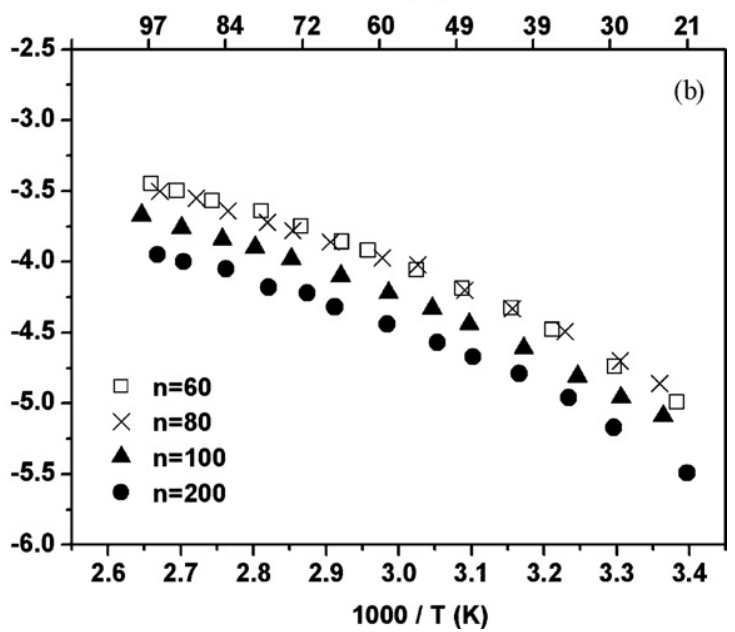

Fig. 2. (a and b) Variation of conductivity of selected d-U(2000) $)_{n}$ LiTFSI electrolytes with temperature.

Fig. 2 illustrates the Arrhenius conductivity plots for the d$\mathrm{U}(2000)_{n}$ LiTFSI ormolytes. All the compositions studied were found to exhibit the non-linear behaviour typical of amorphous polymer electrolytes. The highest room temperature conductivity of this electrolyte system is $3.2 \times 10^{-5} \Omega^{-1} \mathrm{~cm}^{-1}$, registered with the $\mathrm{d}$ $\mathrm{U}(2000)_{35}$ LiTFSI composition. This value is similar to that reported by Armand et al. for the $\mathrm{PEO}_{n}$ LiTFSI electrolyte system [18], and significantly higher than the conductivity of a composition with similar salt content in the Hydrin TX3 terpolymer host matrix [15]. The d-U(2000) ${ }_{10}$ LiTFSI ormolyte showed the highest conductivity $\left(1.2 \times 10^{-3} \Omega^{-1} \mathrm{~cm}^{-1}\right.$ at $\left.95^{\circ} \mathrm{C}\right)$ in the temperature range over which electrolytes were characterized.

The conductivity isotherms derived from conductivity measurements are included in Fig. 3 and reveal the presence of a maximum conductivity for the electrolyte system located in the composition interval $8 \leq n \leq 10$. Ionic conductivity in this hybrid electrolyte increases gradually with salt content for compositions with $n \geq 10$. Total ionic conductivity is generally expected to increase with the number of charge carriers, up to a limit found at about $n=8$. Further increase in salt content beyond this concentration results in a decrease in total ionic conductivity. This observation can be explained by the formation of associated ionic species (e.g., contact ion-pairs, triplets and higher multiplets or ion aggregates) and an increased tendency for ions to form bridging interactions

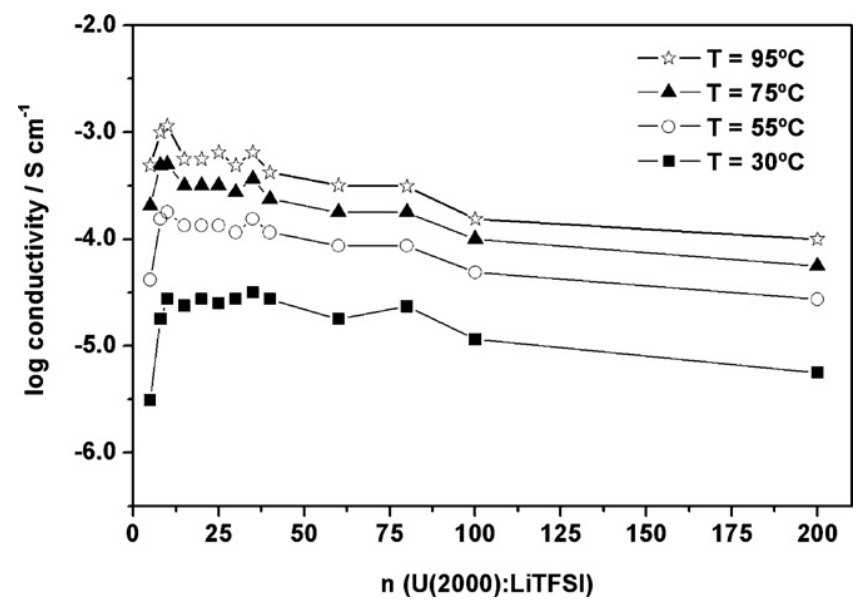

Fig. 3. Isothermal variation of ionic conductivity of d-U(2000) ${ }_{n}$ LiTFSI electrolytes. between adjacent polymer chains, a process designated as "ionic cross-linking". Associated ionic species may be expected to show lower mobility than dissociated ions and the restriction of host matrix segment mobility also contributes to a reduction in the rate of ion transport and electrolyte conductivity.

\subsection{Thermal analysis}

The DSC results obtained with the d-U(2000) $)_{n}$ LiTFSI materials are illustrated in Fig. 4. The absence of any thermal event between 0 and $300{ }^{\circ} \mathrm{C}$ confirms that all the electrolyte compositions over the range of $n$ between 5 and 200 are totally amorphous. The alteration of the guest salt composition in the hybrid matrix over this composition range produces no significant changes in the thermograms recorded. The amorphous nature of the d-U(2000) $)_{n}$ LiTFSI electrolyte system provides a clear advantage relative to the $\mathrm{PEO}_{n}$ LiTFSI system described by Armand et al. [18], since the absence of crystallinity results in improvements in optical, mechanical and electrochemical behaviour.

The onset of thermaldecomposition was estimated from thermogravimetric analysis using the conventional extrapolation of baseline and curve tangent to identify the temperature associated with the initiation of sample weight loss. DSC and TGA analysis (Fig. 5) are consistent with a minimum thermal stability of about $220^{\circ} \mathrm{C}$, although some loss of solvent probably occurs in samples with salt compositions of $n>35$ at temperature of about $150^{\circ} \mathrm{C}$, a value considered acceptable for electrochemical display applications. At higher salt compositions the onset of thermal decomposition is observed to increase (this behaviour is similar to

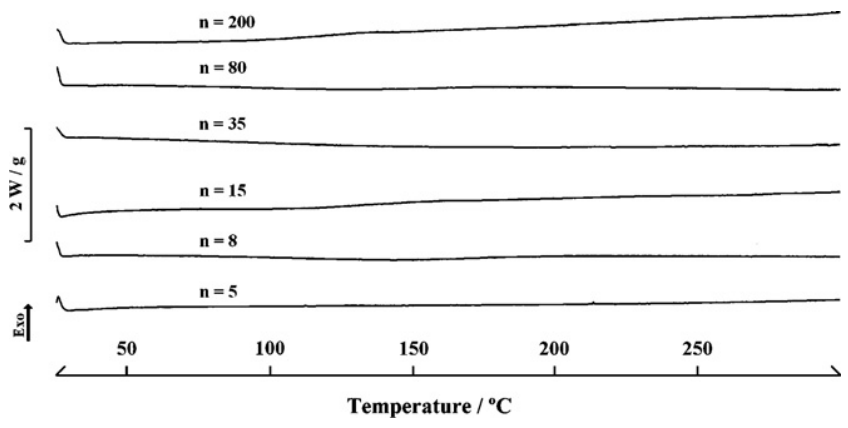

Fig. 4. DSC thermograms of selected d-U(2000) ${ }_{n}$ LiTFSI electrolytes. 


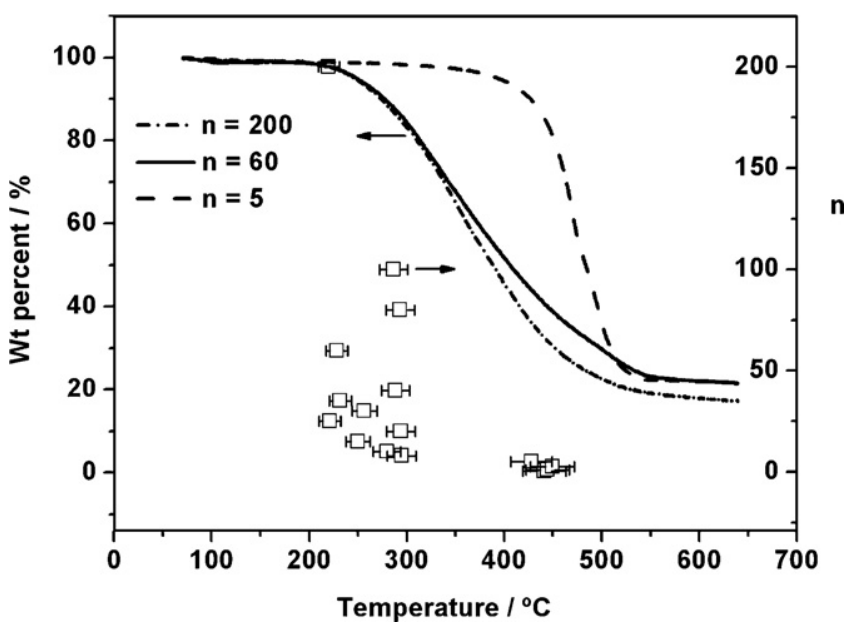

Fig. 5. TGA curves of selected d-U(2000) $)_{n}$ LiTFSI electrolytes. White squares shows extrapolated onset of degradation temperatures from TGA results. The error bars indicate a precision of $\pm 5 \%$ of data on all measurements.

that presented by $\mathrm{d}-\mathrm{U}(2000)_{n} \mathrm{LiClO}_{4}$ ormolytes [13]). In many SPEs an increase in salt content causes a decrease of the onset temperature for thermal decomposition and examples of this behaviour have been reported in several PEO-based formulations [6]. The mechanism of polymer degradation is clearly complex and examples of electrolytes have been reported in which a high salt content may stabilize the electrolyte $[15,20]$. Although detailed studies of the mechanism of decomposition of the d-U(2000) ${ }_{n}$ LiTFSI electrolytes have not been carried out, even the least stable electrolyte composition exceeds the range of operating temperatures required in optical displays by a reasonable margin and this aspect of electrolyte performance is therefore not expected to limit the application of these materials.

The mechanism of ionic transport in this class of electrolyte is closely dependant on the relaxation modes of the polymer host chain segments and therefore lower values of glass transition temperature $\left(T_{\mathrm{g}}\right)$ are generally associated with an electrolyte system that is less constrained by intermolecular interactions. The $T_{\mathrm{g}}$ for selected compositions of the d-U(2000) $)_{n}$ LiTFSI ormolytes is represented in Fig. 6 . In electrolytes with $n>35$ the $T_{\mathrm{g}}$ of electrolytes based on the di-ureasil matrix is almost constant $\left(-59^{\circ} \mathrm{C}\right)$, which suggests that the cation/polymer interactions in this range

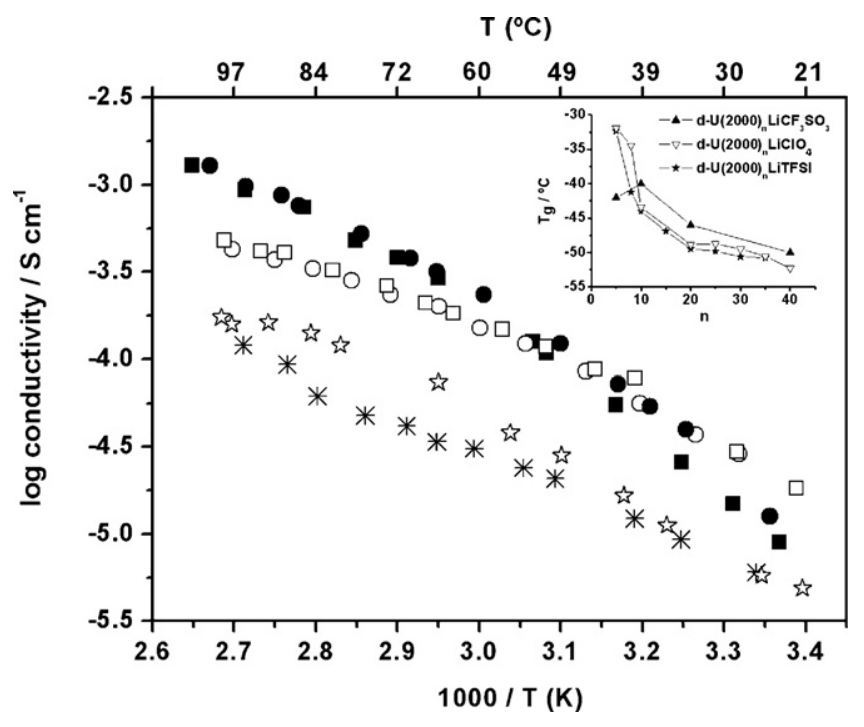

Fig. 7. Comparison of ionic conductivity of d-U(2000) $)_{n} \mathrm{LiTFSI}, \mathrm{d}-\mathrm{U}(2000)_{n} \mathrm{LiClO}_{4}$ and d-U(2000) ${ }_{n} \mathrm{LiCF}_{3} \mathrm{SO}_{3}$ di-ureasils (d-U(2000) ${ }_{8}$ LiTFSI (ם); d-U(2000) ${ }_{10} \mathrm{LiTFSI}$ (•); d-U(2000) $)_{20} \mathrm{LiClO}_{4}(\square) ; \mathrm{d}-\mathrm{U}(2000)_{30} \mathrm{LiClO}_{4}(\bigcirc) ; \mathrm{d}-\mathrm{U}(2000)_{20} \mathrm{LiCF}_{3} \mathrm{SO}_{3}$ (们); d$\mathrm{U}(2000)_{100} \mathrm{LiCF}_{3} \mathrm{SO}_{3}$ (*).

of sample composition are relatively weak and do not influence the $T_{\mathrm{g}}$ values. This effect was also observed in other hybrid organic-inorganic systems [19]. An increase in salt concentration beyond this limit results in a monotonic increase in $T_{\mathrm{g}}$, suggesting that the interactions between the salt and polymer cause a decrease in the mobility of the chain segments of the host matrix. As the salt content is further increased the electrolytes become micro- and macro-scopically less flexible precluding their use in practical devices. This limitation arises not only because of the decrease in ionic conductivity but also because the electrolyte film becomes less flexible and no longer capable of providing a good electrolyte/electrode interfacial contact.

The results presented in Fig. 7 compare the ionic conductivities of the d-U(2000) matrix doped with different lithium salts $[13,19]$. It is evident that at elevated temperatures polymer electrolytes based on LiTFSI exhibit higher conductivity than those prepared with $\mathrm{LiClO}_{4}$ and $\mathrm{LiCF}_{3} \mathrm{SO}_{3}$. This observation may be explained by the lower tendency of LiTFSI to form ion-pairs and higher aggregates. At temperatures close to room temperature, LiTFSI may also
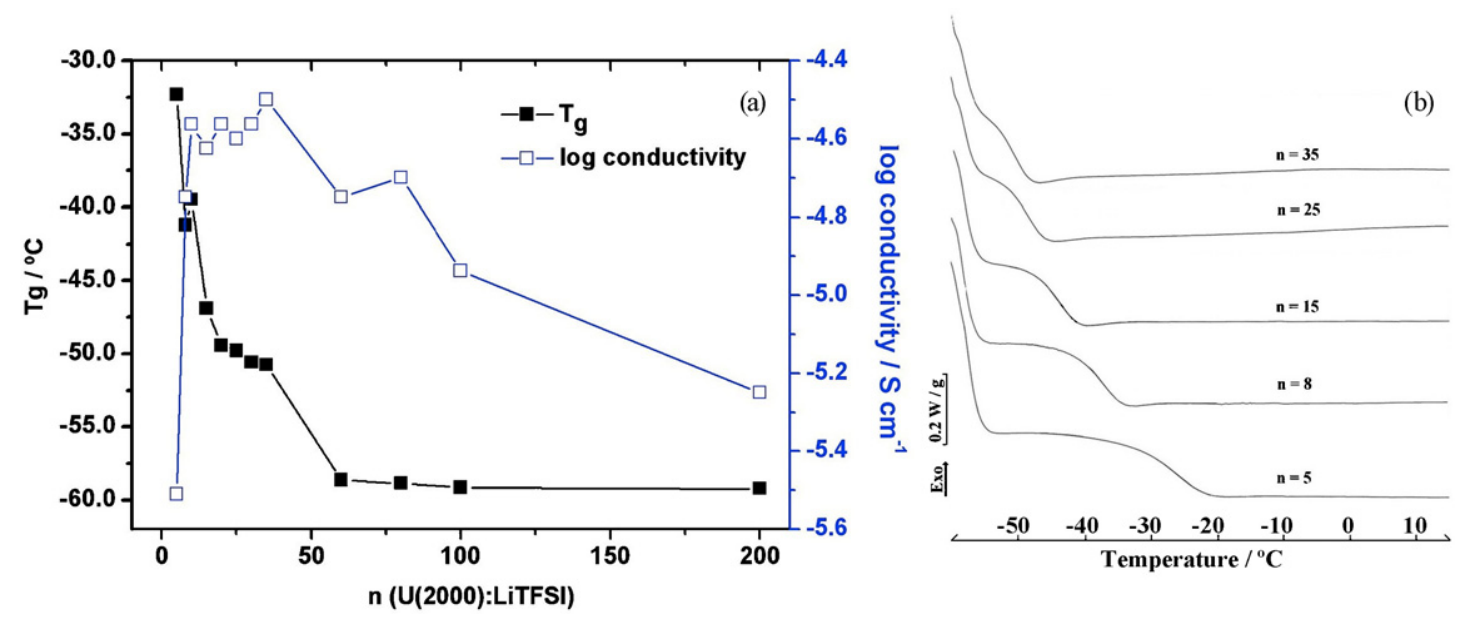

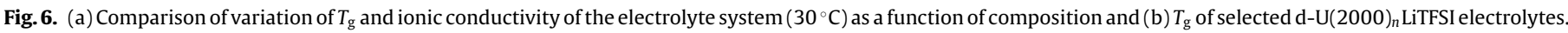


be a better choice for safety reasons. The figure inset illustrates the glass transition temperature of selected compositions of different electrolyte systems. These results are in agreement with the conductivity data and confirm that hybrid materials doped with LiTFSI have lower $T_{\mathrm{g}}$ than those of other electrolyte systems. The increase in $T_{\mathrm{g}}$ with salt concentration is more pronounced in the $\mathrm{LiCF}_{3} \mathrm{SO}_{3}$ and $\mathrm{LiClO}_{4}$-doped electrolytes than in LiTFSI-doped networks. This behaviour has already been reported and explained by the greater capacity of the TFSI anion to delocalize charge, a feature that contributes to a decrease in interactions between polymer chains and reduces their ability to pack into a regular structure $[5,18]$.

The $T_{\mathrm{g}}$ of electrolyte formulations assumes some importance in device assembly as the physical properties as film-spreading, adhesive and sealing properties are influenced by this aspect of electrolyte behaviour. Once again the physical properties of the d-U $(2000)_{n}$ LiTFSI system were shown to be better than those of previously characterized electrolytes $[14,15]$.

\subsection{Electrochemical stability}

The electrochemical stability window is a critical performance parameter for polymer electrolytes, since it may restrict application in practical electrochemical devices. Fig. 8 confirms that the electrochemical stability of the d-U(2000) $)_{10}$ LiTFSI electrolyte, determined by microelectrode cyclic voltammetry over the potential range from -5 to $6 \mathrm{~V}$, is sufficient for optical devices. In the anodic region, the sample is stable up to $5.0 \mathrm{~V}$ vs. $\mathrm{Li} / \mathrm{Li}^{+}$. Lithium deposition begins in the cathodic region at about $-0.5 \mathrm{~V}$ vs. $\mathrm{Li} / \mathrm{Li}^{+}$. These results confirm the applicability of this SPE system to electrochemical devices, a conclusion in accordance with previous studies of oxyethylenebased electrolytes [13,14].

\subsection{Electrochromic device operation}

Electrolyte loss, solvent evaporation and reaction with active electrode material are examples of problems associated with the use of liquid electrolytes in electrochromic displays. The assembly of solid-state devices using polymeric electrolytes represents an advance in the sense that they show improved electrolyte characteristics and may also contribute with additional adhesive, separator and sealant functions.

The coloring and bleaching voltages used in the electrochromic prototypes were 3.5 and $-1.5 \mathrm{~V}$ during 4 and $2 \mathrm{~min}$, respectively. The active layer of the assembled device changed from almost transparent to a blue color associated with $\mathrm{WO}_{3}$ reduction and simultaneous $\mathrm{Li}^{+}$insertion as a result of the application of a pos-

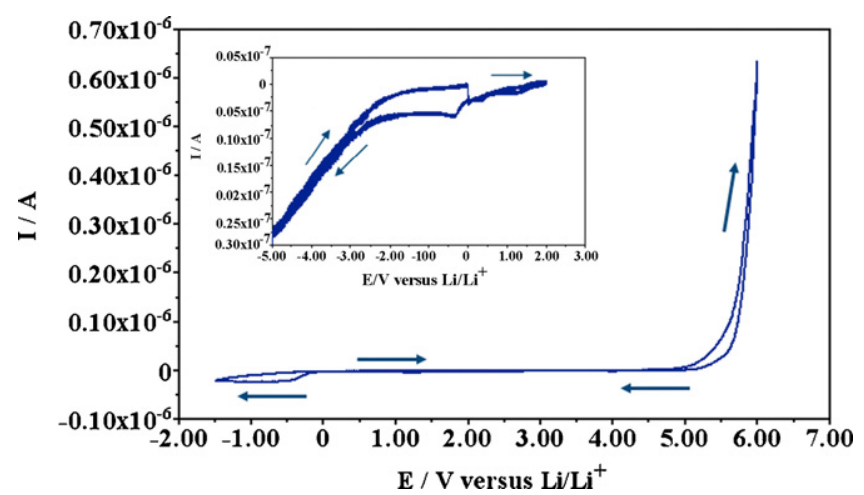

Fig. 8. Voltammogram of d-U(2000) $)_{10}$ LiTFSI electrolyte at a $25 \mu \mathrm{m}$ diameter gold microelectrode vs. $\mathrm{Li} / \mathrm{Li}^{+}$. Initial sweep direction is anodic and sweep rate is $100 \mathrm{mV} \mathrm{s}^{-1}$. (a)
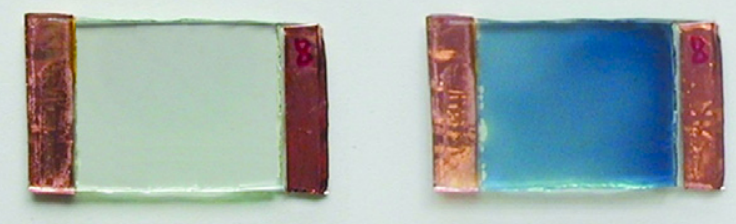

(b)
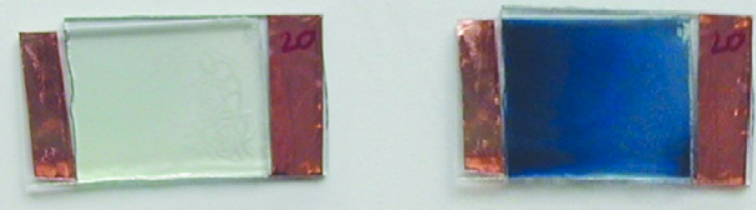

(c)
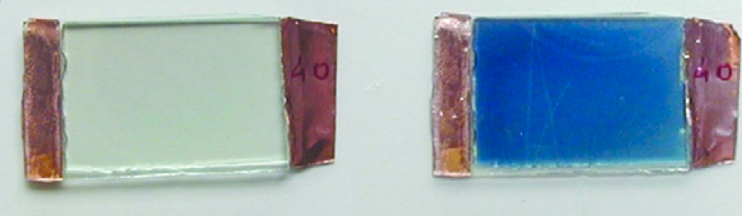

Fig. 9. Electrochromic displays based on different electrolyte component compositions in bleached and colored states: (a) d-U(2000) ${ }_{8}$ LiTFSI, (b) d-U(2000) ${ }_{20}$ LiTFSI, and (c) d-U(2000) $)_{40}$ LiTFSI.

itive voltage (Fig. 9). Inversion of the applied voltage resulted in $\mathrm{WO}_{3}$ oxidation and the device returned to its initial optical state. Fig. 10 illustrates the optical transmittance in the wavelength range $300-900 \mathrm{~nm}$ for the devices based on d-U(2000) $)_{n}$ LiTFSI di-ureasils. It is evident that the electrochromic device provides strong absorption of ultraviolet wavelengths below $350 \mathrm{~nm}$ in both bleached and colored states. Table 1 summarizes the average transmittance and the optical density exhibited by the device. The average transmittance in the visible region of the spectrum was above $70 \%$ for all the bleached samples analyzed. After coloration all structures assembled with d-U(2000)nLiTFSI presented good optical contrast. The structures with $n>8$ presented an optical density above 0.56 , providing an excellent performance in the coloring/bleaching process (Fig. 11).

One of the advantages of electrochromic over liquid crystal displays is the storage capability or memory effect of the electrochromic device in an open-circuit condition. All the devices characterized presented good chemical and electrochemical stability and good memory properties. This study confirms that the application of d-U(2000) $)_{n}$ LiTFSI electrolytes in electrochromic devices improves leakage performance, memory effect and humidity resistance relative to devices employing conventional electrolytes.

Table 1

Average transmittance and optical density exhibited by electrochromic devices using d-U(2000) $)_{n}$ LiTFSI

\begin{tabular}{llll}
\hline Sample & $\begin{array}{l}\text { Transmittance } \\
\text { as-deposited }(\%)\end{array}$ & $\begin{array}{l}\text { Transmittance in } \\
\text { colored state }(\%)\end{array}$ & Optical density \\
\hline $\mathrm{U}(2000)_{1}$ LiTFSI & 73.25 & 41.86 & 0.31 \\
$\mathrm{U}(2000)_{8}$ LiTFSI & 73.04 & 34.57 & 0.41 \\
$\mathrm{U}(2000)_{10}$ LiTFSI & 72.73 & 26.54 & 0.58 \\
$\mathrm{U}(2000)_{20}$ LiTFSI & 70.17 & 22.25 & 0.64 \\
$\mathrm{U}(2000)_{25}$ LiTFSI & 73.13 & 27.28 & 0.57 \\
$\mathrm{U}(2000)_{35}$ LiTFSI & 72.28 & 26.57 & 0.56 \\
$\mathrm{U}(2000)_{40}$ LiTFSI & 69.93 & 21.86 & 0.65 \\
\hline
\end{tabular}



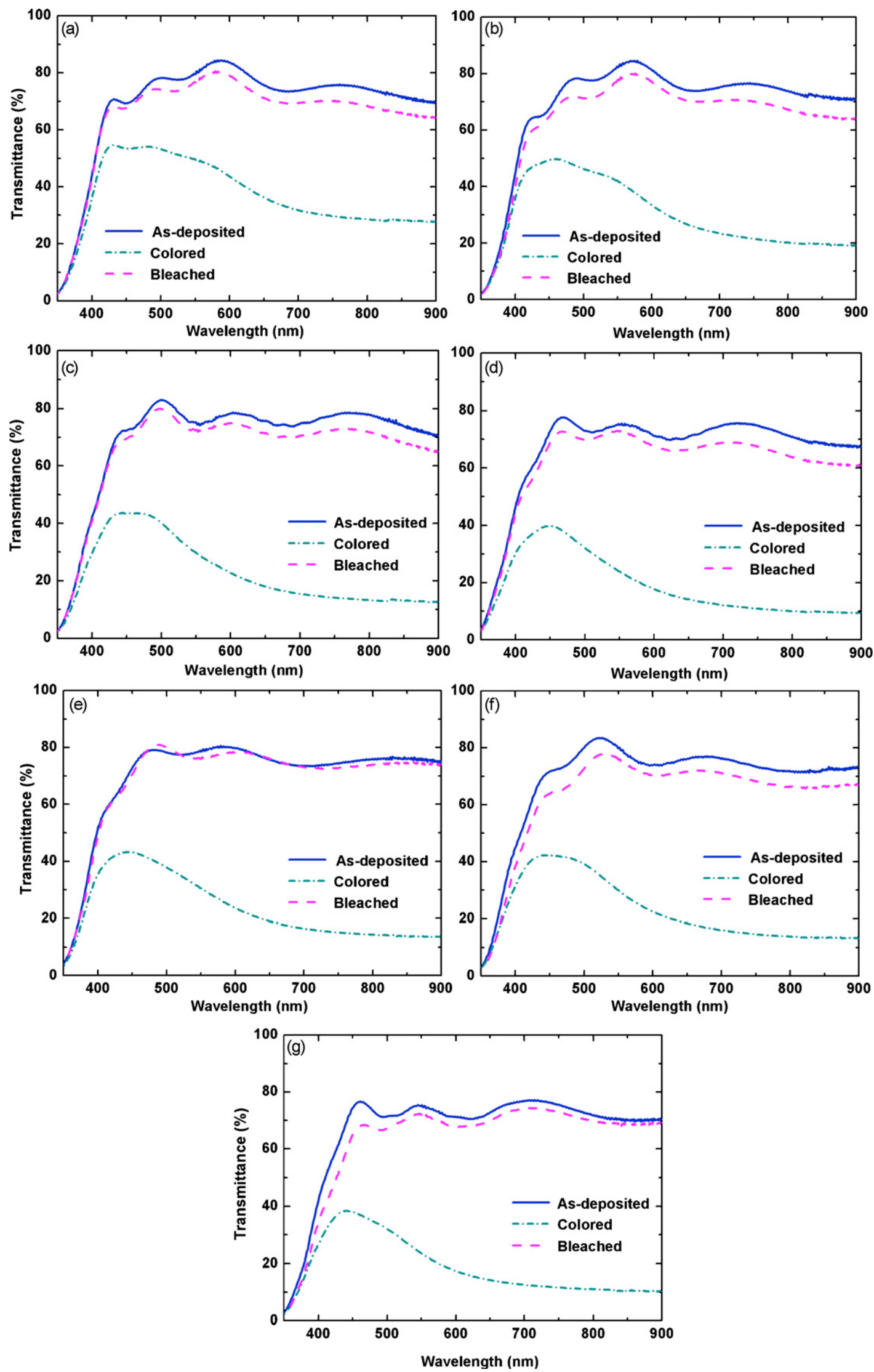

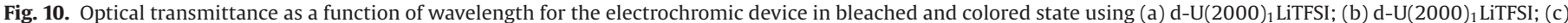
d-U(2000) $)_{8}$ LiTFSI; (d) d-U(2000) ${ }_{10}$ LiTFSI; (e) d-U(2000) ${ }_{20}$ LiTFSI; (f) d-U(2000) ${ }_{35}$ LiTFSI; (g) d-U(2000) ${ }_{40}$ LiTFSI. 


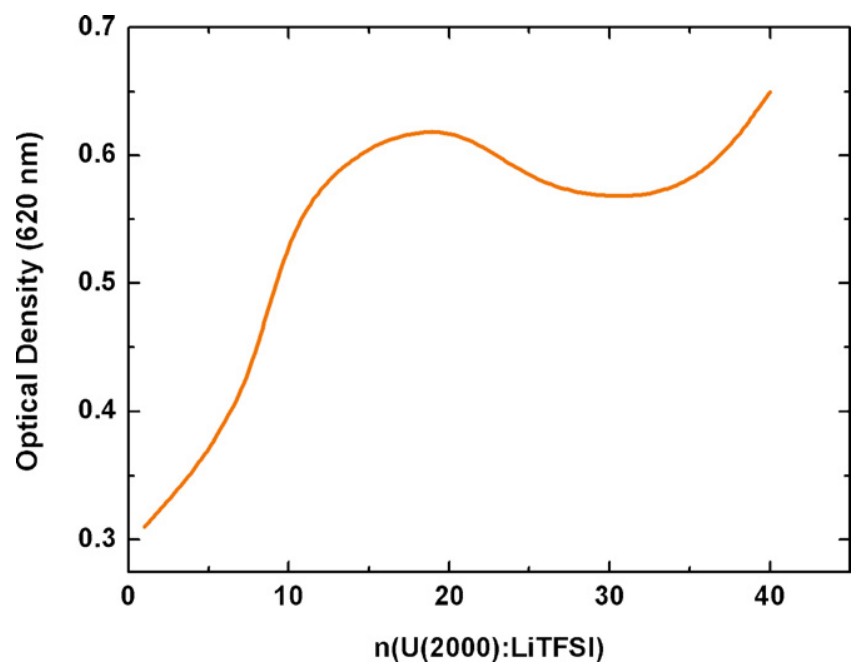

Fig. 11. Optical density of selected electrolytes compositions at $620 \mathrm{~nm}$.

\section{Conclusions}

The preliminary results reported in this study confirm that d-U(2000) $)_{n}$ LiTFSI ormolytes synthesized by the sol-gel route demonstrate suitable thermal, chemical, electrochemical and mechanical properties to support their application in electrochromic devices such as rear-view windows/mirrors, smart windows and time-lapse labels. Although the hybrid electrolytes characterized provide a modest level of ionic conductivity, precluding their application in high-rate devices such as primary or secondary batteries, ion mobility is sufficient to satisfy the demands of typical electrochromic devices. Prototype solid-state electrochromic devices presented encouraging optical contrast, appropriate response times, good off-power image memory and high transmittance in the visible region of the spectrum. In view of the advantage that the sol-gel synthetic method offers in terms of optimization of the properties of hybrid materials through adjustments in the preparative conditions, attention is being devoted to further improvement of key properties of the ormolytes presented.

\section{Acknowledgements}

The authors are pleased to acknowledge the support provided by the University of Minho and the Fundação para a Ciência e a Tecnologia (contracts POCI/QUI/59856/2004, POCTI/ SFA/3/686) for laboratory equipment, research staff grants (contracts SFRH/BD/22707/2005 and SFRH/BD/13559/2003) and travel funds (PCB).

\section{References}

[1] C.M. Lampert, Sol. Energy Mater. Sol. Cells 52 (1998) 207.

[2] E. Syrrakou, S. Papaefthimiou, P. Yianoulis, Sol. Energy Mater. Sol. Cells 85 (2005) 205.

[3] T. Lukaszewicz, A. Ravinski, I. Makoed, Nonlinear Anal.: Model. Control 9(2004) 363.

[4] V. de Zea Bermudez, D. Baril, J.Y. Sanchez, M. Armand, C. Poinsignon, A. HugotLe Goff, in: C.G. Granqvist, C.M. Lampert (Eds.), Proceedings SPIE of Optical Materials Technology for Energy Efficiency and Solar Energy Conversion XI: Chromogenics for Smart Windows, vol. 1728, 1992, p. 180;

(a) S.M. Gomes Correia, V. de Zea Bermudez, M.M. Silva, S. Barros, R.A. Sá Ferreira, L.D. Carlos, A.P. Passos de Almeida, M.J. Smith, Electrochim. Acta 47 (15) (2002) 2421 [Corrigendum Electrochimica Acta 49 (2004) 5029];

(b) V. de Zea Bermudez, S.M. Gomes Correia, M.M. Silva, S. Barros, R.A. Sá Ferreira, L.D. Carlos, M.J. Smith, C. Molina, K. Dahmouche, S.J.L. Ribeiro, J. Sol-Gel Sci. Technol. $26(1-3)(2003) 375$;

(c) S.M. Gomes Correia, V. de Zea Bermudez, M.M. Silva, S. Barros, R.A. Sá Ferreira, L.D. Carlos, A.P. Passos de Almeida, M.J. Smith, Solid State Ionics 156 (1-2) (2003) 85;

(d) S.C. Nunes, V. de Zea Bermudez, D. OstrovskiI, M.M. Silva, S. Barros, M.J. Smith, R.A. Sá Ferreira, L.D. Carlos, J. Rocha, E. Morales, J. Electrochem. Soc. 152 (2) (2005) A429-A438;

(e) S.C. Nunes, V. de Zea Bermudez, M.M. Silva, S. Barros, M.J. Smith, E. Morales, L.D. Carlos, J. Rocha, Solid State Ionics 176 (17) (2005) 1591;

(f) S.C. Nunes, V. de Zea Bermudez, M.M. Silva, M.J. Smith, E. Morales, R.A. Sá Ferreira, L.D. Carlos, J. Rocha, Solid State Sci. 8 (2006) 1484.

[5] C.J. Brinker, G. Scherer, Sol-Gel Science: The Physics and Chemistry of Sol-Gel Processing, Academic Press, San Diego, CA, 1990.

[6] (a) F.M. Gray, Solid Polymer Electrolytes, Fundamentals and Technological Applications, VCH, New York, 1991;

(b) F.M. Gray, Polymer Electrolytes, RSC Materials Monographs, Royal Society of Chemistry, London, 1997;

(c) M.B. Armand, in: J.R. MacCallum, C.A. Vincent (Eds.), Polymer Electrolyte Reviews-1, Elsevier, London, 1987, p. 1.

[7] M. Armand, Adv. Mater. 2 (1990) 127.

[8] D. Ravaine, A. Seminel, Y. Charbouillot, M.J. Vincens, Non-Cryst. Solids 82 (1986) 210.

[9] P. Judeinstein, J. Livage, A. Zarudianski, R. Rose, Solid State Ionics 28-30 (1988) 1722.

[10] P. Judeinstein, J. Timan, M. Stamm, H. Schmidt, Chem. Mater. 6 (1994) 127.

[11] L.D. Carlos, V. de Zea Bermudez, M.C. Duarte, M.M. Silva, C.J. Silva, M.J. Smith, M. Assunção, L. Alcácer, in: C. Ronda, T. Welker (Eds.), Physics and Chemistry of Luminescent Materials VI, Electrochemical Society Proceedings, vol. 97-29, San Francisco, 1998, p. 352.

[12] V. de Zea Bermudez, L.D. Carlos, M.C. Duarte, M.M. Silva, C.J. Silva, M.J. Smith, M. Assunção, L.J. Alcácer, J. Alloys Compd. 275 (1998) 21.

[13] M.M. Silva, S.C. Nunes, P.C. Barbosa, A. Evans, V. de Zea Bermudez, M.J. Smith, D. Ostrovskii, Electrochim. Acta 52 (2006) 1542.

[14] P.C. Barbosa, L.C. Rodrigues, M.M. Silva, M.J. Smith, J. Power Sources 180 (2008) 607.

[15] L.C. Rodrigues, P.C. Barbosa, M.M. Silva, M.J. Smith, Electrochim. Acta 53 (2007) 1427.

[16] E. Fortunato, A. Pimentel, A. Gonçalves, A. Marques, R. Martins, Thin Solid Films 502 (2006) 104.

[17] C.J.R. Silva, M.J. Smith, Electrochim. Acta 40 (1995) 2389.

[18] M. Armand, W. Gorecki, R. Andrani, in: B. Scrosati (Ed.), Proceedings of the 2nd International Symposium on Polymer Electrolytes, Elsevier, 1990, p. 91.

[19] S.C. Nunes, V. de Zea Bermudez, D. Ostrovskii, M.M. Silva, S. Barros, M.J. Smith, L.D. Carlos, J. Rocha, E. Morales, J. Electrochem. Soc. 152 (2005) A429.

[20] P.C. Barbosa, M.M. Silva, M.J. Smith, A. Gonçalves, E. Fortunato, Electrochim. Acta 52 (2007) 2938. 